\title{
Diameter and Spiral Thickness Optimization of Knuckle Joint Using Neural Network
}

\author{
Pankaj Dulani ${ }^{1}$, S. A. K. Jilani ${ }^{2}$ \\ ${ }^{1}$ Rungta College of Engineering \& Technology, Bhilai, Chhattisgarh, India \\ ${ }^{2}$ Professor, Rungta College of Engineering \& Technology, Bhilai, Chhattisgarh, India
}

\begin{abstract}
The project study presents the problem of the failure of the knuckle pin in any mechanism for general due to crushing, tearing and shearing. As per the functionality of the knuckle pin the pin is suitable for retaining of the knuckle and no loading conditions is determined over it but due to the manufacturability of the knuckle itself the failure of knuckle is undertaken thus the possible solution is presented in this thesis. The papers related to this topic are studied for any recent advancement in the knuckle pin while no relevant problem is defined and possible remedy is determined. Also the study focuses on the optimization of design parameters kept in mind for the knuckle pin. The Neural Network Tool, a nontraditional global optimization technique has been used as the solution methodology for its inherent advantages. Optimal results so obtained are compared with remodeled knuckle pin with stress minimizing effect considered as a key factor. The aim of the present paper is to study calculate the stresses in Knuckle joint using analytical method. Further study in this direction can made by using various directions of the pin and the capacity to withstand load.
\end{abstract}

Keywords: knuckle joint pin, spiral pin, Neural Network Tool.

\section{Introduction}

Knuckle joint is a type of mechanical joint used in structures, to connect two intersecting cylindrical rods, whose axes lie on the same plane. It permits some angular movement between the cylindrical rods (in their plane). It is specially designed to withstand tensile loads. A knuckle joint is used to connect two rods which are under the action of tensile loads whereas, if the joint is guided, compressive load may be supported by rods. A knuckle joint can be easily disconnected when required. Its uses are link of a cycle chain, tie road joint for roof truss, valve rod joint with eccentric rod, pump rod joint, tension link in bridge structure and lever and rod connection of various types.

\section{Stress in Knuckle Joint}

The simple definition of stress is that is force divided by area. If the force is perpendicular to the area and pulling away from it, the stress is tensile. If the force is perpendicular to area and pushing towards it, the stress is compressive. Both tensile and compressive stresses come under general category of direct stress.

If the force is parallel to area to cause sliding of one area over other the stress is shearing. If two bodies are in contact and pressed against each other the stress is bearing. The magnitude of bearing stress will be the compressing force divided by contact area between two bodies. The bearing stress is compressive in nature and is also called crushing stress

\section{Failure of Knuckle}

A knuckle joint may be failed on the following three modes

1. Shear failure of pin (single shear).

2. Crushing of pin against rod.

3. Tensile failure of flat end bar.
The failure mechanism of knuckle joint has been studied by several investigators. Jones has reported that shear failure due to torsional loading is the normal failure mechanism in many engineering components. Pantazopoulos et.al [17] has studied the failure of a knuckle joint of a universal coupling system. It was mentioned that torsional overload of the knuckle joint is the major cause of failure. However, in many cases it was reported that wear of material due to severe friction leading to delamination wear $[18,19]$.

\section{Materials for Knuckle Joint}

The materials used for making knuckle joint is 30C8 Steel and the chemical compositions are $\mathrm{C}-0.25-0.35, \mathrm{Mn}-0.60-$ 0.90, Si- $0.10-0.35$, P- 0.030, S- 0.035 .

\section{Problems in Knuckle Joint}

In Knuckle joint there is high varying intensity and nature of loads due to which various problem are encountered which are discussed below: The knuckle is such an important component for the joining the parallel shaft or members because it is relate with much system and it carry varies of load. A good durability of knuckle is required to make sure it well functioning. Many problems that appear today are about the bent or damaged of the knuckle. This will affect proper alignment. And this will cause in high maintenance's cost, and can cause an accident that will lose of life. An efficiency solution should be finding and improve in order to prevent this problem. Through this project, a study about the durability and stress analysis of the knuckle can help in choosing a better material and design, and analysis which design is better that will have a great strength and can sustain more loading when it is in service. 


\section{International Journal of Science and Research (IJSR) \\ ISSN (Online): 2319-7064 \\ Index Copernicus Value (2013): 6.14 | Impact Factor (2014): 5.611}

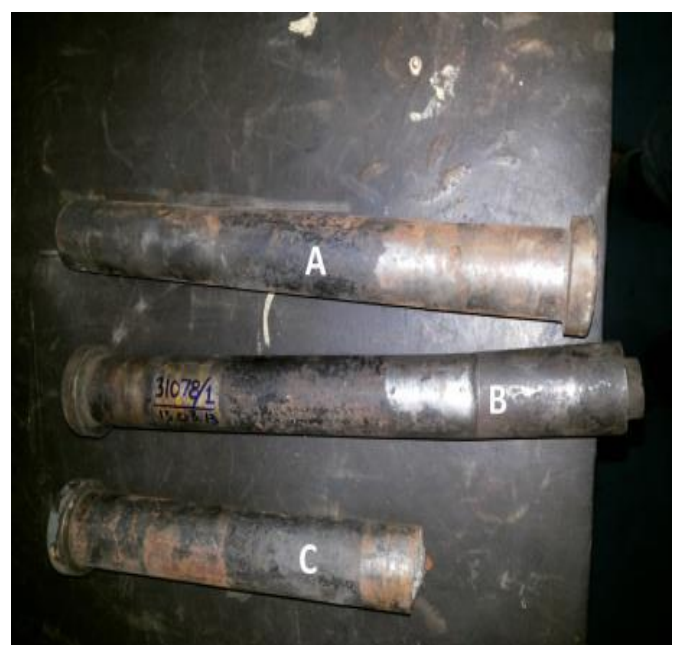

Figure 1: Damaged Knuckle Pin [17]

\section{Methodology}

A series of study on the current knuckle has been done in the early stage of the research. Through this project, a study about the durability and stress analysis of the knuckle can help in choosing a better material and new spiral design, and analysis which design is better that will have a great strength and can sustain more loading when it is in service. To avoid this damaging affect a proposed design of knuckle is analyzed with different parameters of knuckle in following steps:

- Geometric Modeling in CREO.

- Comparison between solid pin and spiral pin.

- Finite Element Analysis with varying Boundary Conditions.

- Optimization using NN Tool

The chosen design parameters undergo an optimization process to get the optimum shape and material usage. CREO is used as designing software in order to achieve number of designs which will generate different values of output parameters for optimizing the design. The optimized design was then remodeled in the CREO to get the accurate shape and dimension. Figure 2 shows the flow chart of work.

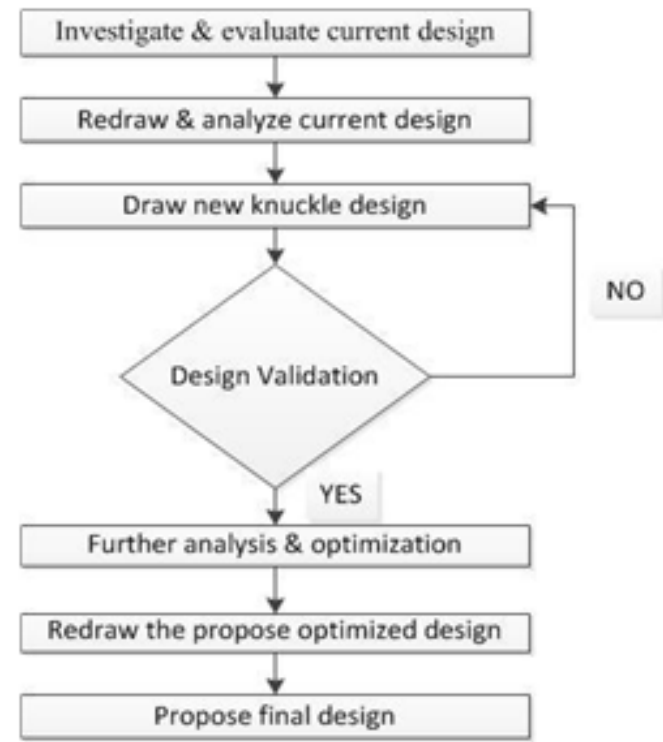

Figure 2: Design Methodology Flowchart

\subsection{Geometric Modeling and Boundary Conditions}

The numerical static simulation needs input of 3D geometry of domain under consideration. The domain is divided into small elements called mesh. Numerical methods are used for discretisation of governing equations over an element

The geometry of knuckle joint is modeled in CREO .The 3D view of complete domain is shown in figure 3 . The first step in analyzing any machine assembly using FEM package is to draw a solid model. The solid model should incorporate all the complexities and features of the real life assembly. It is often seen in literature that the accuracy of obtained results from ANSYS are always directly dependent on the accuracy of the solid model to its physical form.

In this case based on the dimensions actually measured for a fixed load, a model has been prepared. Location of Forks and a pin is similar to as it is in actual case. The solid model is than imported into the FEM module of ANSYS and meshed using solid 109152 elements

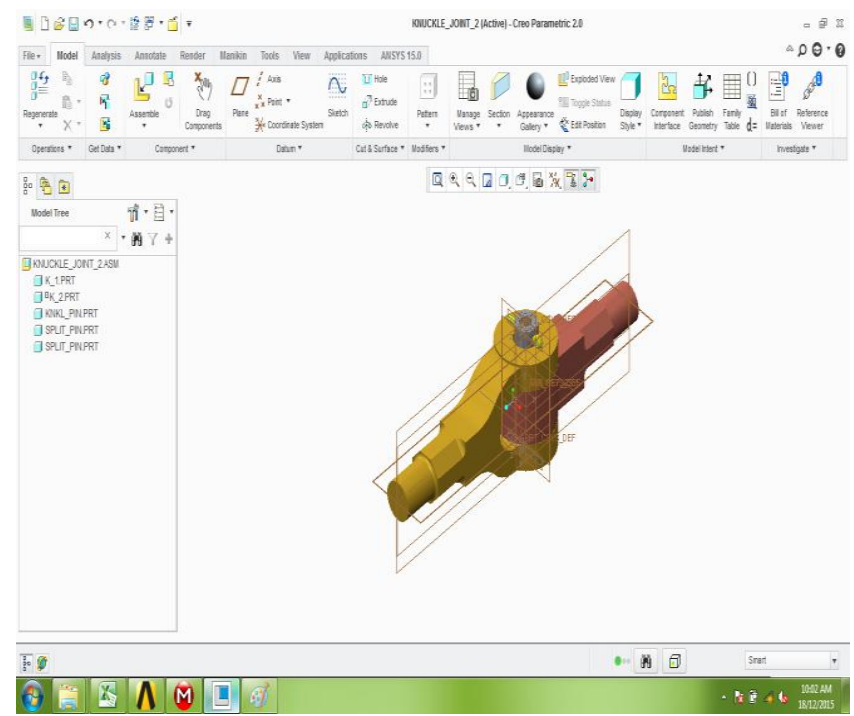

Figure 3: Geometric Modeling of Knuckle Joint

\subsection{Common Input Data}

The material properties and some common input data used for material are mentioned in Table 1. Here material selected for designing of knuckle joint is 30C8 Steel.

Table 1: Setting Model Parameters

\begin{tabular}{|c|c|}
\hline Density & $7.85 \mathrm{e}-006 \mathrm{~kg} / \mathrm{mm} 3$ \\
\hline Coefficient of Thermal Expansion & $1.2 \mathrm{e}-005 \mathrm{C}^{\wedge}-1$ \\
\hline Specific Heat & $4.34 \mathrm{e}+005 \mathrm{~mJ} \mathrm{~kg}^{\wedge}-1 \mathrm{C}^{\wedge}-1$ \\
\hline Thermal Conductivity & $6.05 \mathrm{e}-002 \mathrm{~W} \mathrm{~mm}{ }^{\wedge}-1 \mathrm{C}^{\wedge}-1$ \\
\hline Resistivity & $1.7 \mathrm{e}-004 \mathrm{ohm} \mathrm{mm}$ \\
\hline Compressive Yield Strength Mpa & 250 \\
\hline Tensile Yield Strength Mpa & 250 \\
\hline Tensile Ultimate Strength Mpa & 465 \\
\hline
\end{tabular}

\section{Optimization for Spiral Pin Parameters}

After comparison between solid and spiral pin used in knuckle joint it is revealed that spiral pin is new and better 


\section{International Journal of Science and Research (IJSR) \\ ISSN (Online): 2319-7064 \\ Index Copernicus Value (2013): 6.14 | Impact Factor (2014): 5.611}

design from stress point of view having less value of stress, and further analysis can be done for optimization of its diameter and thickness of plate from which the pin will be made. Here thickness of plate is termed as spiral thickness for future reference.

To optimizing the performance of a knuckle joint design in context of crushing and shearing stress (maximum) scenario, different ranges of design parameters are proposed in table to optimize the performance of knuckle joint

Table 2: Setting Model Parameters

\begin{tabular}{|c|c|c|}
\hline SET & Diameter of Pin $(\mathrm{mm})$ & Spiral Thickness $(\mathrm{mm})$ \\
\hline SET-1 & 30 & 7.5 \\
\hline SET-2 & 32 & 7.75 \\
\hline SET-3 & 34 & 8 \\
\hline SET-4 & 36 & 8.25 \\
\hline
\end{tabular}

Finally, analytical results obtained from two application examples with different design parameters by the use of ANSYS and force are presented for the further analysis of the mechanical system. This allows for predicting the influence of design parameter changes, in order to minimize stresses, strain, and deformation. Table 3 shows the ANSYS generated results for the knuckle joint.

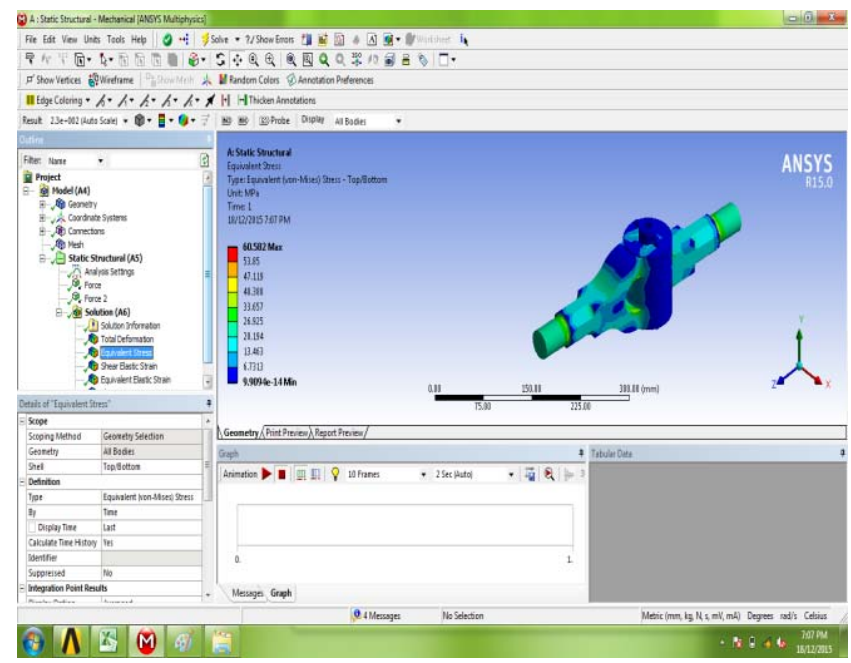

Figure 4: Stress Analysis using Spiral Pin

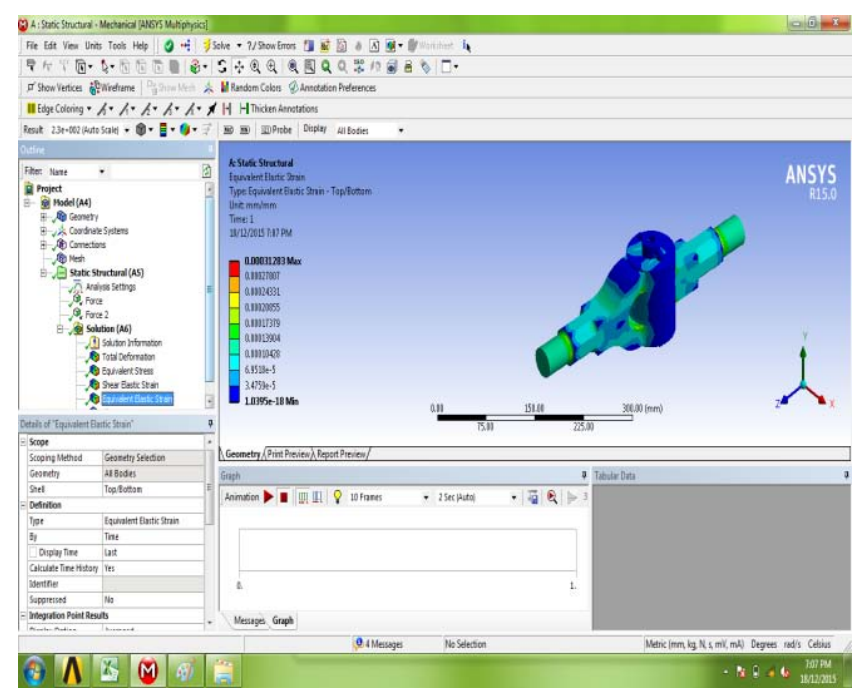

Figure 5: Strain Analysis using Spiral Pin
Table 3: Setting Model Parameters Analysis Results

\begin{tabular}{|c|c|c|c|c|}
\hline SET & $\begin{array}{c}\text { Force } \\
(\text { KN })\end{array}$ & $\begin{array}{c}\text { Max. Stress } \\
(\text { N/mm } 2)\end{array}$ & Strain & $\begin{array}{c}\text { Deformation } \\
(\mathrm{mm})\end{array}$ \\
\hline SET-1 & 25 & 38.61 & 0.000302 & 0.0977 \\
\hline SET-1 & 30 & 46.32 & 0.000298 & 0.17133 \\
\hline SET-1 & 35 & 52.68 & 0.000289 & 0.21121 \\
\hline SET-2 & 25 & 30.85 & 0.000245 & 0.0879 \\
\hline SET-2 & 30 & 36.95 & 0.000241 & 0.1456 \\
\hline SET-2 & 35 & 43.58 & 0.000237 & 0.20025 \\
\hline SET-3 & 25 & 26.58 & 0.00022 & 0.0789 \\
\hline SET-3 & 30 & 31.25 & 0.000217 & 0.13268 \\
\hline SET-3 & 35 & 38.29 & 0.000212 & 0.19756 \\
\hline SET-4 & 25 & 21.93 & 0.000199 & 0.06238 \\
\hline SET-4 & 30 & 27.39 & 0.000185 & 0.12258 \\
\hline SET-4 & 35 & 34.28 & 0.000182 & 0.17538 \\
\hline
\end{tabular}

\section{Results}

The graphs below illustrates the comparison between the design parameters of the mechanical system (spiral pin) generated by ANSYS software and neural network optimization in order to provide an optimized set of design parameters for a given value of force applied on the knuckle joint.

Table 4: Stress Comparison between actual and NN Tool

Data

\begin{tabular}{|c|c|c|}
\hline S.No & \multicolumn{2}{|c|}{ STRESS (N/mm2) } \\
\hline & ANSYS & NEURAL NETWORK \\
\hline 1. & 38.61 & 27.8968 \\
\hline 2. & 46.32 & 22.1364 \\
\hline 3. & 52.68 & 24.1131 \\
\hline 4. & 30.85 & 36.2697 \\
\hline 5. & 36.95 & 28.2635 \\
\hline 6. & 43.58 & 26.8095 \\
\hline 7. & 26.58 & 27.5733 \\
\hline 8. & 31.25 & 23.842 \\
\hline 9. & 38.29 & 28.4112 \\
\hline 10. & 21.93 & 27.8976 \\
\hline 11 & 27.39 & 26.7887 \\
\hline 12. & 34.28 & 29.0987 \\
\hline
\end{tabular}

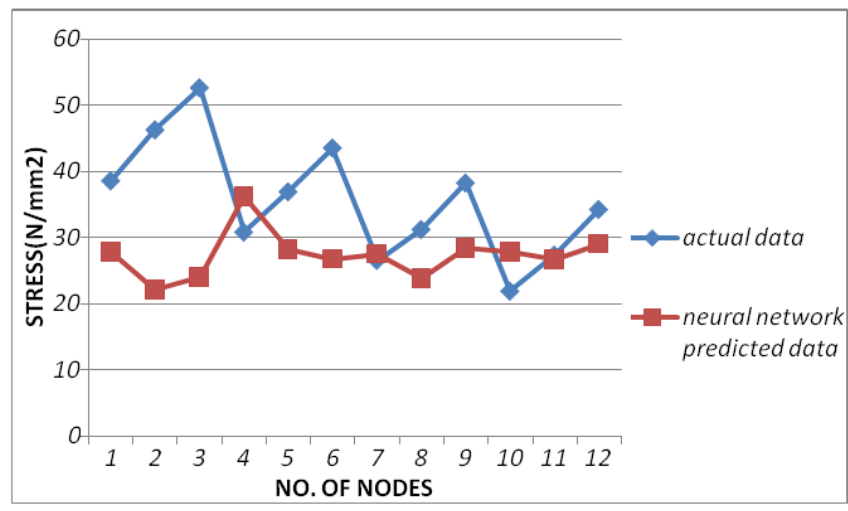

Figure 6: Stress Comparison between actual and NN Tool Data

Above figure and table represents stress comparison between ANSYS generated and neural network generated values to obtain the optimized value of stress. 


\section{International Journal of Science and Research (IJSR) \\ ISSN (Online): 2319-7064}

Index Copernicus Value (2013): 6.14 | Impact Factor (2014): 5.611

Table 5: Strain Comparison between actual and NN Tool

Data

\begin{tabular}{|c|c|c|}
\hline S.No & \multicolumn{2}{|c|}{ STRAIN } \\
\hline & ANSYS & NEURAL NETWORK \\
\hline 1. & 0.000302 & 0.0022096 \\
\hline 2. & 0.00298 & 0.0012848 \\
\hline 3. & 0.000289 & 0.00058482 \\
\hline 4. & 0.000245 & 0.0011074 \\
\hline 5. & 0.000241 & 0.0002461 \\
\hline 6. & 0.000237 & 0.00023246 \\
\hline 7. & 0.00022 & 0.0010791 \\
\hline 8. & 0.000217 & 0.00051496 \\
\hline 9. & 0.000212 & 0.0002498 \\
\hline 10. & 0.000199 & 0.00023628 \\
\hline 11. & 0.000185 & 0.00110075 \\
\hline 12. & 0.000182 & 0.00051785 \\
\hline
\end{tabular}

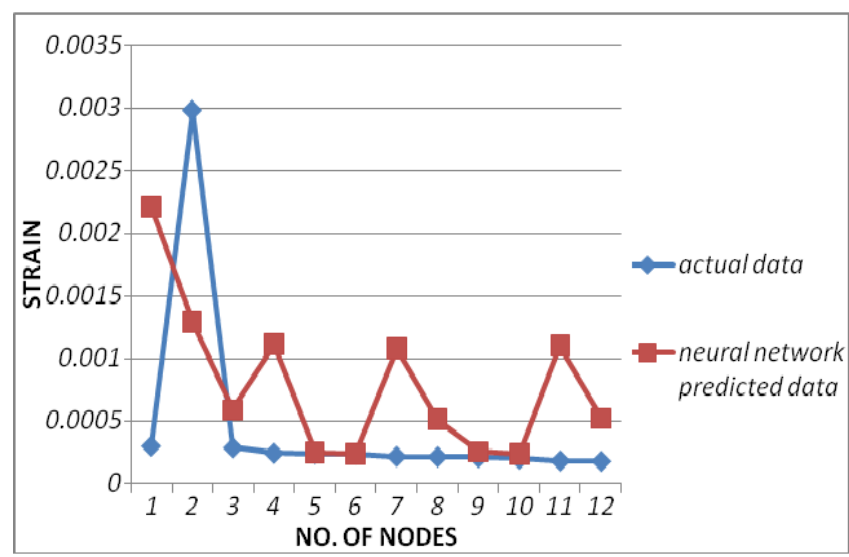

Figure 7: Strain Comparison between actual and NN Tool Data

Above figure and table represents strain comparison between ANSYS generated and neural network generated values to obtain the optimized value of strain.

Table 6: Deformation Comparison between actual and NN Tool Data

\begin{tabular}{|c|c|c|}
\hline S.No & \multicolumn{2}{|c|}{ DEFORMATION(mm) } \\
\hline & ANSYS & NEURAL NETWORK \\
\hline 1. & 0.0977 & 0.10621 \\
\hline 2. & 0.17133 & 0.20133 \\
\hline 3. & 0.21121 & 0.20403 \\
\hline 4. & 0.0879 & 0.21039 \\
\hline 5. & 0.1456 & 0.21015 \\
\hline 6. & 0.20025 & 0.20868 \\
\hline 7. & 0.0789 & 0.21087 \\
\hline 8. & 0.13268 & 0.21082 \\
\hline 9. & 0.19756 & 0.17865 \\
\hline 10. & 0.06238 & 0.12432 \\
\hline 11. & 0.12258 & 0.12877 \\
\hline 12. & 0.17538 & 0.15643 \\
\hline
\end{tabular}

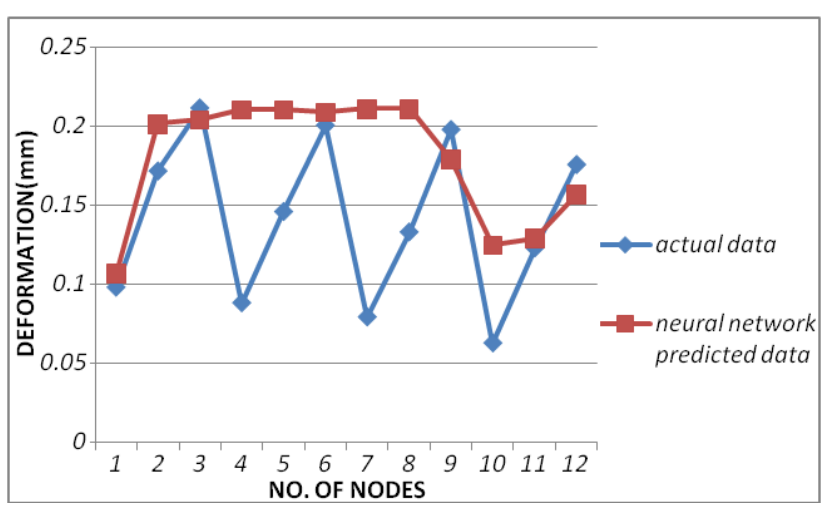

Figure 8: Deformation Comparison between actual and NN Tool Data

Above figure and table represents deformation comparison between ANSYS generated and neural network generated values to obtain the optimized value of deformation.

Table 7: Diameter of Pin Comparison between actual and NN Tool Data

\begin{tabular}{|c|c|c|}
\hline S.No & \multicolumn{2}{|c|}{ DIAMETER OF PIN(mm) } \\
\hline & ANSYS & NEURAL NETWORK \\
\hline 1. & 30 & 35.908 \\
\hline 2. & 30 & 35.5013 \\
\hline 3. & 30 & 35.7431 \\
\hline 4. & 32 & 35.8238 \\
\hline 5. & 32 & 33.3643 \\
\hline 6. & 32 & 35.7986 \\
\hline 7. & 34 & 35.5123 \\
\hline 8. & 34 & 30.6228 \\
\hline 9. & 34 & 35.789 \\
\hline 10. & 36 & 33.876 \\
\hline 11. & 36 & 35.907 \\
\hline 12. & 36 & 33.3671 \\
\hline
\end{tabular}

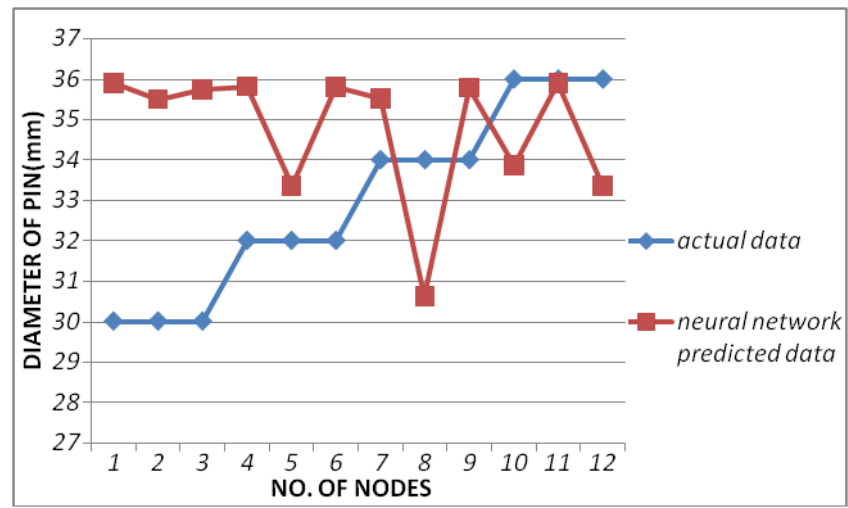

Figure 9: Diameter Comparison between actual and NN Tool Data

Above figure and table represents diameter of pin comparison between ANSYS generated and neural network generated values to obtain the optimized value of diameter of pin. 


\section{International Journal of Science and Research (IJSR) \\ ISSN (Online): 2319-7064}

Index Copernicus Value (2013): 6.14 | Impact Factor (2014): 5.611

Table 8: Spiral Thickness Comparison between actual and NN Tool Data

\begin{tabular}{|c|c|c|}
\hline S.No & \multicolumn{2}{|c|}{ SPIRAL THICKNESS(mm/side) } \\
\hline & ANSYS & NEURAL NETWORK \\
\hline 1. & 7.5 & 10.6807 \\
\hline 2. & 7.5 & 8.4259 \\
\hline 3. & 7.5 & 8.1433 \\
\hline 4. & 7.75 & 10.7737 \\
\hline 5. & 7.75 & 6.8271 \\
\hline 6. & 7.75 & 10.8799 \\
\hline 7. & 8 & 9.743 \\
\hline 8. & 8 & 5.9947 \\
\hline 9. & 8 & 5.5343 \\
\hline 10. & 8.25 & 7.7778 \\
\hline 11. & 8.25 & 7.899 \\
\hline 12. & 8.25 & 5.242 \\
\hline
\end{tabular}

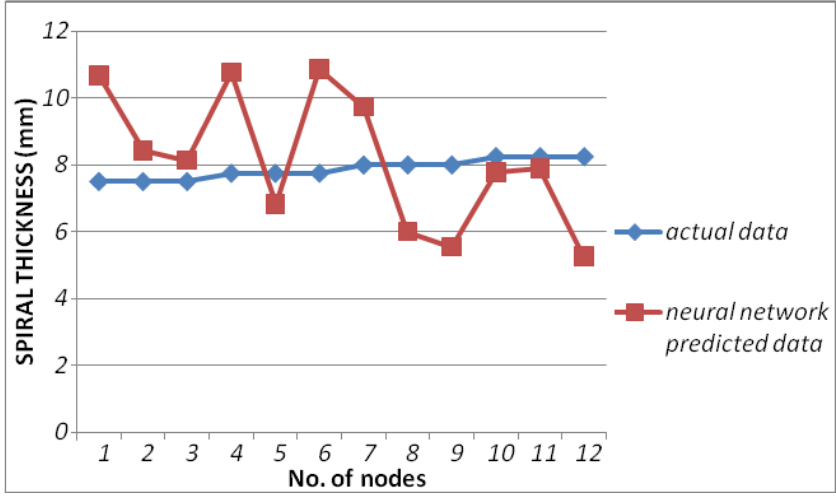

Figure 10: Spiral Thickness Comparison Between Actual and NN Tool Data

Above figure and table represents spiral thickness comparison between ANSYS generated and neural network generated values to obtain the optimized value of spiral thickness.

Above all figure and table represents force comparison between ANSYS generated and neural network generated values to obtain the optimized value of force. The Values thereby generated helps to choose an appropriate and optimized set of design parameters as well as force input which is being depicted in the table given below.

Table 9: Optimized Design Parameters from NN tool

\begin{tabular}{|c|c|c|}
\hline Force $(\mathrm{KN})$ & Diameter of Pin $(\mathrm{mm})$ & Spiral Thickness $(\mathrm{mm})$ \\
\hline 28.362 & 30.6228 & 5.9947 \\
\hline
\end{tabular}

\section{Conclusion}

The results generated for spiral pin with 4 number of set of input parameters can be further analyzed to obtain the optimum value of diameter and thickness of pin with the help of NN tool. After remodeling of the knuckle joint using the predicted optimized parameters obtained by neural network the model is used to generate the value of stress which is compared with the neural network result in order to prove that optimized model is better as compared to the previously selected four models. The optimization process includes the generation of diameter of pin at a given pin thickness and force applied to the knuckle joint mechanism. This finally concludes the objective of the study being conducted. The table below presents a comparison between value of ANSYS stress and optimized stress for a given spiral thickness and diameter of pin.

Table 10: Comparison between optimized and computational results

\begin{tabular}{|c|c|c|c|}
\hline \multicolumn{2}{|c|}{ Design Parameters } & \multicolumn{2}{c|}{ Stress(N/mm2) } \\
\hline $\begin{array}{c}\text { Spiral } \\
\text { thickness(mm) }\end{array}$ & $\begin{array}{c}\text { Diameter of } \\
\text { pin }\end{array}$ & $\begin{array}{c}\text { Neural Network } \\
\text { Based Result }\end{array}$ & $\begin{array}{c}\text { ANSYS Based } \\
\text { Result }\end{array}$ \\
\hline 5.9947 & 30.6228 & 23.842 & 22.9989 \\
\hline
\end{tabular}

\section{References}

[1] Knuckle Structure for Coupler by Horst Thomas Kaufhold, Chicago on 31st Dec, 1974.

[2] C.A. Brebbia, ed, Finite Element Systems, A Handbook, Springer-Verlag, Berlin, 1982.

[3] Knuckle Structure to Prevent Knuckle Pin Failure in a Railway Coupler Presented by William O. Elliott \& Pittsburgh on 3rd Feb, 1987.

[4] Womack, J. P., Jones, D. T., \& Roos, D. (1990), "The Machine That Changed The World", New York: Rawson Associates, 11-15.

[5] Mac Carthy, L. (1993), "A new classification scheme for flexible manufacturing systems", International Journal of Production Research, 31, 299-309.

[6] Ramasesh R. V \& Jayakumar M. D. (1991), "Measurement of $\mathrm{mfg}$ flexibility: a value based approach", Journal of operational, management, 10(4), 446-468. Doi: 10.1016/0272-6963(91)90005-I.

[7] Y.L. Lee and Others, "Durability Design Process of a Vehicle Suspension Component", Journal of testing and evaluation, 23(5), 1995, pp. 354-363

[8] Roslan Abd Rahman, Mohd Nasir Tamin, Ojo Kurdi "Stress analysis of heavy duty truck chassis as a preliminary data for its fatigue life prediction using FEM" Jurnal Mekanikal December 2008, No. 26, 76 85

[9] Prof R. L. Jhala, K. D. Kothari "Component Fatigue Behaviors and Life Predictions of a Steering Knuckle Using Finite Element Analysis "Proceedings of the International Multiconference of Engineers and Computer Scientists 2009 Vol II IMECS 2009, March 18 - 20, 2009, Hong Kong

[10] G. Pantazopoulos, A. Sampani, E. Tsagaridis“Torsional failure of a knuckle joint of a universal steel coupling system during operation" Engineering Failure Analysis, Volume 14, Issue1, ISSN1350-6307.

[11]Dinesh Shinde, Kanak Kalita, "FEA Analysis of Knuckle Joint Pin Used in Tractor Trailer" ARPN Journal of Engineering and Applied Sciences, Vol 10, NO. 5, MARCH 2015, ISSN 1819-6608

[12] Beranger, A. S., Berard, J. Y., and Vittori, J. F., "A Fatigue Life Assessment Methodology for Automotive Components," Fatigue Design of Components, SIS Publication 22, Proceedings of the Second International Symposium on Fatigue Design, FD'95, 5-8 September, 1995, Helsinki, Finland, Marquis, G.,Solin, J. Eds., 1997, pp. 17- 25.

[13] N.K.Ingole, D.V. Bhope "Stress Analysis of Tractor Trailer Chassis for Self Weight Reduction” International 
Journal of Engineering Science and Technology (IJEST), ISSN: 0975-5462 Vol. 3 No. 9 September 2011

[14]Viraj Rajendra Kulkarni, "Optimization and Finite Element Analysis of Steering Knuckle"2013 India Altair Technology conference.

[15]K. Kalita. "Stress Concentration Mitigation in Clamped Steel Plates". International Journal of Scientific World (IJSW). 2(1).

[16] Hemant B.Patil, Sharad D.Kachave, Eknath R.Deore, "Stress Analysis of Automotive Chassis with Various Thicknesses", IOSR Journal of Mechanical and Civil Engineering (IOSR-JMCE), April 2013

[17] Kanak Kalita, Salil Halder. "Stress Concentration Minimization of 2D Simply Supported Perforated Steel Plate", International Journal on Theoretical and Applied Research in Mechanical Engineering,ISSN (Print): 2319-3182, Volume -3, Issue-1, January, 2014

[18] Ravindra S. Dharpure, Prof D. M. Mate, "Study and Analysis of Pin of Knuckle Joint in Train" JETIR, Volume 1 Issue 3, (ISSN-2349-5162)

[19] Nishant Vibhav Saxena, Dr. Rohit Rajvaidya, "Study \& Analysis of Knuckle Joint with the Replacement of Material by Using Teflon", Int. Journal of Engineering Research and Applications, ISSN: 2248-9622, Vol. 5, Issue 3, (Part -4) March 2015, pp.67-72

[20] Wan Mansor Wan Muhamad, Endra Sujatmika, Hisham Hamid, \& Faris Tarlochan, "Design Improvement of Steering Knuckle Component using Shape Optimization" International Journal of Advanced Computer Science, Vol. 2, No. 2, pp. 65-69, Feb. 2012. 